\title{
Plant Productivity in Response to LED Lighting
}

\author{
Gioia D. Massa ${ }^{1}$ \\ Department of Horticulture and Landscape Architecture, Purdue University, \\ 625 Agriculture Mall Drive, West Lafayette, IN 47907-2010 \\ Hyeon-Hye Kim and Raymond M. Wheeler \\ Space Life Sciences Laboratory, Kennedy Space Center, FL 32899 \\ Cary A. Mitchell \\ Department of Horticulture and Landscape Architecture, Purdue University, \\ 625 Agriculture Mall Drive, West Lafayette, IN 47907-2010
}

Additional index words. controlled environment agriculture, light quality, light-emitting diode, edema, intracanopy lighting

\begin{abstract}
Light-emitting diodes (LEDs) have tremendous potential as supplemental or sole-source lighting systems for crop production both on and off earth. Their small size, durability, long operating lifetime, wavelength specificity, relatively cool emitting surfaces, and linear photon output with electrical input current make these solid-state light sources ideal for use in plant lighting designs. Because the output waveband of LEDs (single color, nonphosphor-coated) is much narrower than that of traditional sources of electric lighting used for plant growth, one challenge in designing an optimum plant lighting system is to determine wavelengths essential for specific crops. Work at NASA's Kennedy Space Center has focused on the proportion of blue light required for normal plant growth as well as the optimum wavelength of red and the red/far-red ratio. The addition of green wavelengths for improved plant growth as well as for visual monitoring of plant status has been addressed. Like with other light sources, spectral quality of LEDs can have dramatic effects on crop anatomy and morphology as well as nutrient uptake and pathogen development. Work at Purdue University has focused on geometry of light delivery to improve energy use efficiency of a crop lighting system. Additionally, foliar intumescence developing in the absence of ultraviolet light or other less understood stimuli could become a serious limitation for some crops lighted solely by narrow-band LEDs. Ways to prevent this condition are being investigated. Potential LED benefits to the controlled environment agriculture industry are numerous and more work needs to be done to position horticulture at the forefront of this promising technology.
\end{abstract}

Light-emitting diodes (LEDs) have a variety of advantages over traditional forms of horticultural lighting. Their small size, durability, long lifetime, cool emitting temperature, and the option to select specific wavelengths for a targeted plant response make LEDs more suitable for plant-based uses than many other light sources. These advantages, coupled with new developments in wavelength availability, light output, and energy conversion efficiency, place us on the brink of a revolution in horticultural lighting.

For horticultural researchers and crop producers to benefit from LED use, a variety of preliminary findings should be considered. A number of studies have been performed at the University of Wisconsin, at NASA's Kennedy Space Center, and at Purdue University to examine the usefulness of LEDs as a sole source or as supplemental lighting for plant growth in space such as part of a lifesupport system on Mars. Although the vast majority of LED work thus far has been performed with food crops, observed plant responses likely would benefit ornamental crops as well. The findings of these and other studies can help guide selection of LED types and positioning for a variety of purposes depending on crop type and desired responses. A review of key studies, discussion of potential applications, and posing of open questions follows. For more information on plant responses to light quality, see

Received for publication 3 Mar. 2008. Accepted for publication 2 Apr. 2008.

${ }^{1}$ To whom reprint requests should be addressed; e-mailgmassa@purdue.edu the reviews by Devlin et al. (2007) and Folta and Childers (2008).

\section{EARLY TESTING AND THE POTENTIAL FOR LEDS IN PLANT GROWTH SYSTEMS}

Bula et al. (1991) at the University of Wisconsin first suggested using LEDs to grow plants and reported that growth of lettuce plants under red LEDs supplemented with blue fluorescent (BF) lamps was equivalent to that under cool-white fluorescent (CWF) plus incandescent lamps. At the time of that study, blue LEDs were not yet widely available, so BF lamps were used as an alternative. Subsequent testing by that group showed that hypocotyls and cotyledons of lettuce seedlings under red $(660 \mathrm{~nm})$ LEDs became elongated, but that effect could be prevented by adding at least $15 \mu \mathrm{mol} \cdot \mathrm{m}^{-2} \cdot \mathrm{s}^{-1}$ of blue light (Hoenecke et al., 1992). These findings inspired continued development of LED lighting systems for small plant growth chambers that flew several times aboard NASA's Space Shuttle (Barta et al., 1992) and which were used to grow wheat (Triticum aestivum L.) and Brassica rapa L. seedlings (Morrow et al., 1995), potato (Solanum tuberosum L.) leaf cuttings (Croxdale et al., 1997), Arabidopsis thaliana (Stankovic et al., 2002), and soybeans [Glycine $\max$ (L.) Merr] (Zhou, 2005). The potential of LEDs for terrestrial plant research continued to build, in which comparisons of red LED and xenonarc-illuminated kudzu [Pueraria lobata (Willd.) Ohwi] leaves showed slight differences in stomatal conductance $\left(g_{\mathrm{S}}\right)$ but similar photosynthetic responses to photosynthetic photon flux $(P P F)$ and $\mathrm{CO}_{2}$ (Tennessen et al., 1994). A comparison of photosynthetic rates of strawberry (Fragaria xananassa L.) leaves with red $(660 \mathrm{~nm})$ or blue $(450 \mathrm{~nm})$ LEDs showed higher quantum efficiencies under the reds (Yanagi et al., 1996a). Spectral measurements of red $(660 \mathrm{~nm})$ LEDs, red LEDs plus BF, red LEDs plus far-red (FR, $735 \mathrm{~nm}$ ) LEDs, and metal halide (MH) lamps indicated similar phytochrome photostationary states but significantly higher levels of long-wave radiation from the $\mathrm{MH}$ lamps, indicating the thermal advantages of using LEDs in plant growth systems (Brown et al., 1995). More recent studies have showed that rice plants grown under a combination of red $(660 \mathrm{~nm})$ and blue $(470 \mathrm{~nm})$ LEDs sustained higher leaf photosynthetic rates than did leaves from plants grown under red LEDs only (Matsuda et al., 2004). The authors attributed this to higher nitrogen content of the blue light-supplemented plants.

\section{THE IMPORTANCE OF BLUE LIGHT}

The use of red LED light to power photosynthesis has been widely accepted for two primary reasons. First, the McCree curves (Sager and McFarlane, 1997) indicate that red wavelengths (600 to $700 \mathrm{~nm}$ ) are efficiently absorbed by plant pigments; second, early LEDs were red with the most efficient emitting at $660 \mathrm{~nm}$, close to an absorption peak of chlorophyll. They also saturated phytochrome, creating a high-Pfr photostationary state in the absence of FR or dark reversion. The other main wavelength included in early studies has been in the blue region (400 to $500 \mathrm{~nm}$ ) of the visible 
spectrum. The amount of blue light required or optimal for different species is an ongoing question. Blue light has a variety of important photomorphogenic roles in plants, including stomatal control (Schwartz and Zeiger, 1984), which affects water relations and $\mathrm{CO}_{2}$ exchange, stem elongation (Cosgrove, 1981), and phototropism (Blaauw and Blaauw-Jansen, 1970).

Initial studies by the Wisconsin group demonstrated the need to supplement highoutput red LEDs with some blue light to get acceptable plant growth (Hoenecke et al., 1992). Subsequent studies at the Kennedy Space Center showed wheat seedlings germinating under $500 \mu \mathrm{mol} \cdot \mathrm{m}^{-2} \cdot \mathrm{s}^{-1}$ of red LED light failed to develop chlorophyll but that supplementation with only $30 \mu \mathrm{mol} \cdot \mathrm{m}^{-2} \cdot \mathrm{s}^{-1}$ of blue light, or just reducing red $P P F$ to 100 $\mu \mathrm{mol} \cdot \mathrm{m}^{-2} \cdot \mathrm{s}^{-1}$, restored chlorophyll synthesis (Tripathy and Brown, 1995). Potato plantlets grown in vitro increased in chlorophyll under red LEDs when $P P F$ was increased from 11 to $64 \mu \mathrm{mol} \cdot \mathrm{m}^{-2} \cdot \mathrm{s}^{-1}$, but all plants under red LEDs increased in shoot length compared with control plants under white fluorescent lighting (Miyashita et al., 1997). Studies by Yanagi et al. (1996b) showed that lettuce plants grown under red LEDs alone had more leaves and longer stems than plants grown under blue LEDs only. Goins et al. (1997) used LEDs as sole-source lighting for chambergrown wheat and compared red LEDs alone, red with $1 \% \mathrm{BF}$, and red with $10 \%$ $\mathrm{BF}$ with daylight fluorescent lamps. Plants were grown under a 24-h photoperiod at $350 \mu \mathrm{mol} \cdot \mathrm{m}^{-2} \cdot \mathrm{s}^{-1} \mathrm{PPF}$ in each case. The findings showed that wheat could complete a life cycle with red light alone, although added blue light produced larger plants with greater numbers of seeds. One percent blue $\left(\approx 3 \mu \mathrm{mol} \cdot \mathrm{m}^{-2} \cdot \mathrm{s}^{-1}\right)$ was sufficient to keep culm-leaf and flag-leaf length equal to control lengths. However, $10 \%$ blue (35 $\mu \mathrm{mol} \cdot \mathrm{m}^{-2} \cdot \mathrm{s}^{-1}$ ) was needed to produce the same number of tillers as control plants (Goins et al., 1997). Shoot dry matter and photosynthetic rates increased with increasing levels of blue light.

Yorio et al. (1998) summarized previous blue light work and reported that yield of lettuce, spinach, and radish crops grown under red LEDs alone was reduced compared with when $35 \mu \mathrm{mol} \cdot \mathrm{m}^{-2} \cdot \mathrm{s}^{-1}$ of blue fluorescence was included to give the same final $P P F$. This combination of red plus blue was sufficient to give yields comparable to those found under CWF at the same PPF. However, blue light requirements for traits such as stem elongation seem to be genotypespecific, at least in potato (Yorio et al., 1998). Although the potato work was not carried out with LEDs, it has implications for the use of narrow-waveband LEDs in horticultural crop production. It is possible that certain cultivars might grow well with less costly and more efficient single-wavelength LED lighting systems.

Goins et al. (1998) examined the growth and seed yield of Arabidopsis plants grown from seed to seed under LED lights. Plants were grown either under $175 \mu \mathrm{mol} \cdot \mathrm{m}^{-2} \cdot \mathrm{s}^{-1}$ CWF or the same total $P P F$ from red LEDs including $0 \%, 1 \%$, or $10 \% \mathrm{BF}$. Like with wheat, Arabidopsis plants grown under red alone could produce seeds. However, the time to bolting increased with decreasing blue light level with plants under red alone taking twice as long to flower and set seed as those under CWF. Also, plants grown with $10 \% \mathrm{BF}$ had half the seeds of those grown under CWF, whereas those with $0 \%$ or $1 \%$ $\mathrm{BF}$ had one-tenth the seeds of the CWF plants. Leaf morphology was abnormal for plants grown under red alone with downward curling of leaf margins and spiral growth of the rosette, but inclusion of blue light at any level restored normal leaf morphology. Seeds germinated at a high percentage under all light types tested, irrespective of the light environment in which they were produced (Goins et al., 1998).

Yorio et al. (2001) grew lettuce, radish, and spinach plants under red LEDs with or without $10 \%$ BF $\left(\approx 30 \mu \mathrm{mol} \cdot \mathrm{m}^{-2} \cdot \mathrm{s}^{-1}\right)$ and compared growth with that of plants grown under CWF at the same $P P F$. Spinach and radish plants grown under CWF had significantly higher dry weights than plants grown under LEDs. Their results indicated that adding blue to the red LED light produced growth of lettuce nearly equal to that under CWF, but this was not sufficient for spinach and radish plants. Measurements of leaf photosynthetic rates and $g_{\mathrm{S}}$ showed no clear differences, although those rates tended to be lower for plants lighted solely with red LEDs (Yorio et al., 2001).

\section{STUDIES WITH FAR-RED AND INFRARED LEDS}

Schuerger et al. (1997) examined changes in leaf anatomy of pepper under different color combinations of light. They used red $(660 \mathrm{~nm})$ LEDs combined either with FR $(735 \mathrm{~nm})$ LEDs or BF lamps compared with MH controls, all at the same PPF. Their results indicated that leaf thickness and number of chloroplasts per cell depended much more on the level of blue light than the red:FR ratio. Treatments without added blue had the lowest leaf cross-sectional area, whereas red $+1 \% \mathrm{BF}$ was intermediate in response, and $\mathrm{MH}$ controls (at 20\% blue) had the greatest leaf thickness and most chloroplasts (Schuerger et al., 1997). Several other studies using FR LEDs are discussed by Kim et al. (2005) examining plant morphology, disease development, and nitrate accumulation. Until recently, it was difficult to obtain LED arrays with a wide light spectrum tunable at different emission peaks, but with the rapid, ongoing development of LED technology, such studies can now be conducted using multispectral arrays that generate a variety of colors or even white light.

Johnson et al. (1996) examined effects of infrared (IR) LEDs of $880 \mathrm{~nm}$ and $935 \mathrm{~nm}$ on etiolated oat seedlings. Spectroradiometric analysis of those long-wavelength sources showed that actual peak emission wave- lengths averaged $916 \mathrm{~nm}$ and $958 \mathrm{~nm}$, respectively. Compared with dark-grown controls, seedlings grown with 880 (916)$\mathrm{nm}$ LEDs had shorter overall length but more advanced leaf emergence than either dark- or 935 (958)-nm-grown seedlings. Also, the proportion of mesocotyl tissue was significantly higher for seedlings grown with either IR source or dark grown, whereas the proportion of coleoptile tissue was significantly lower. An ancillary observation was that the IR LED radiation made seedlings significantly straighter and trained them to the gravity vector. The authors proposed the activation of a "gravitropism photon-sensing system" with potential involvement of phytochrome (Johnson et al., 1996).

\section{GREEN LIGHT}

Many previous studies indicate that even with blue light added to red LEDs, plant growth is still better under white light. Certainly to humans, plants grown under red plus blue light appear purplish gray, and disease and disorder become difficult to diagnose (Fig. 1). One possible solution is using a small amount of green light. To test this hypothesis, Kim et al. (2004a) grew lettuce plants under red and blue LEDs with and without $5 \%\left(6 \mu \mathrm{mol} \cdot \mathrm{m}^{-2} \cdot \mathrm{s}^{-1}\right)$ green from LEDs with both treatments at the same total PPF $\left(136 \mu \mathrm{mol} \cdot \mathrm{m}^{-2} \cdot \mathrm{s}^{-1}\right)$. They observed no impact on lettuce growth with all measurable characteristics such as photosynthesis rate, shoot weight, leaf area, and leaf number being the same with and without green. They followed this work with another lettuce study to determine the effects of higher levels of green light under a total $P P F$ of $150 \mu \mathrm{mol} \cdot \mathrm{m}^{-2} \cdot \mathrm{s}^{-1}$ and an 18 -h photoperiod (Kim et al., 2004b). They used red and blue LEDs with and without green fluorescence (GF) (24\% green for RGB or $0 \%$ green for $\mathrm{RB}$ ), GF alone (86\% green), and CWF (51\% green) and demonstrated that lettuce plants grown with RGB had higher fresh and dry weights and greater leaf area than those grown with CWF or RB alone. Plants grown under GF had the least biomass of all treatments. Further work with the same system (Kim et al., 2004c) examined $g_{S}$. Although lettuce grown under CWF showed greater maximal $g_{\mathrm{S}}$ than under RB, RGB, or $\mathrm{GF}$, dry mass accumulation was highest in the RGB treatment, indicating that $g_{\mathrm{S}}$ did not limit carbon assimilation under the growth conditions provided. Additionally, the authors demonstrated that $g_{\mathrm{S}}$ could be changed reversibly in response to narrow waveband light, even for plants grown under CWF (Kim et al., 2004c). Kim et al. (2006) summarized the experiments with green supplementation of red and blue LED light and concluded that light sources consisting of more than $50 \%$ green cause reductions in plant growth, whereas combinations including up to $24 \%$ green enhance growth for some species. For more information on plant responses to green light, see Folta and Maruhnich (2007). 

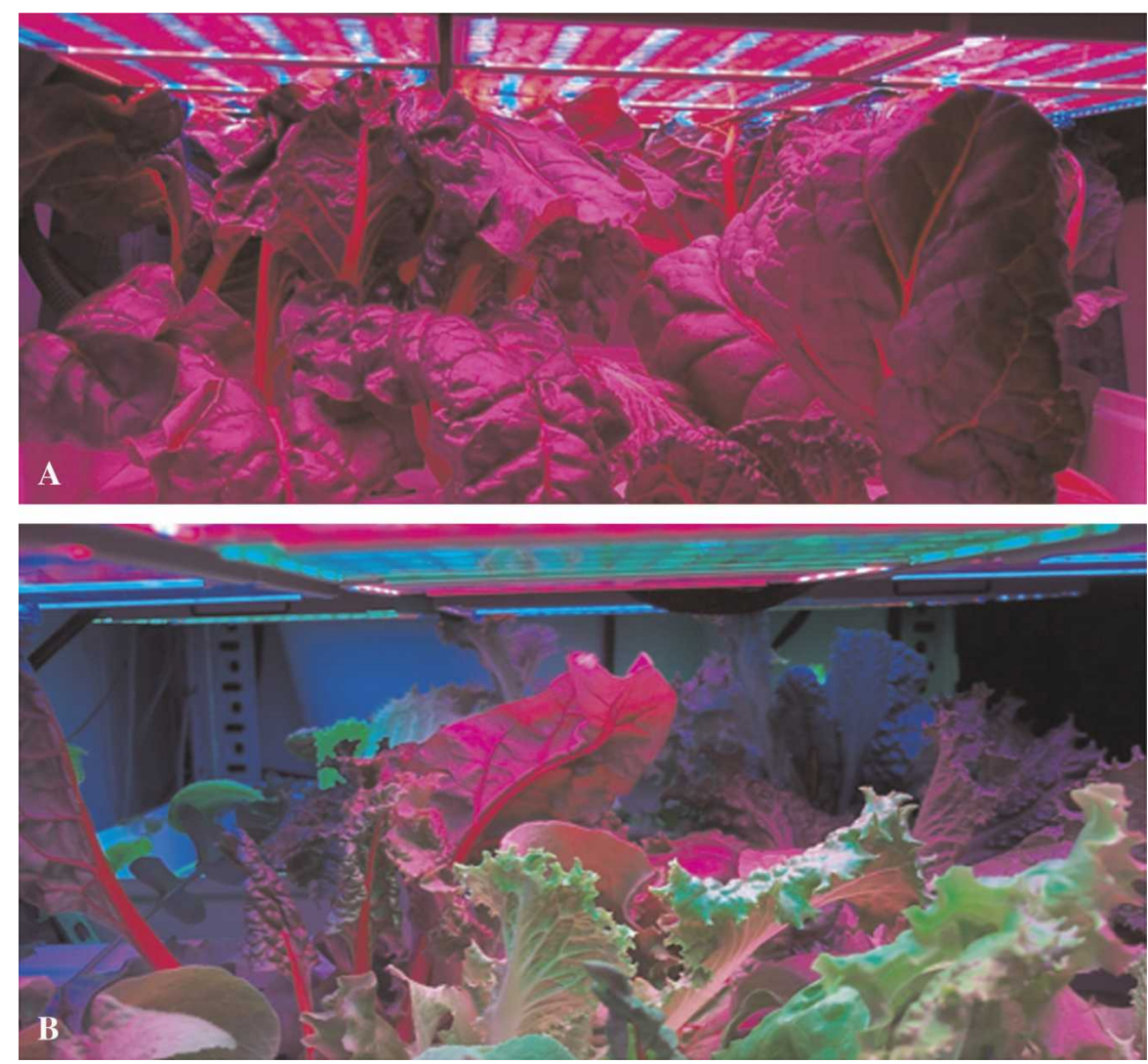

Fig. 1. Chard and lettuce plants growing under red plus blue (A) or red plus blue plus green (B) lightemitting diodes (LEDs). Plants grow equally well under both combinations but leaves appear purplish under the red plus blue, making visual assessment of plant condition difficult. Addition of green LED light resolves this problem for human visual perception.

\section{LAMP PLACEMENT TO INCREASE LIGHTING EFFICIENCY}

In addition to light quality, the position of light sources relative to the photosynthetic surfaces of plants has a large effect on crop productivity. Because the radiation energy intercepted by a surface from a point source is related to the inverse square of the distance between them (Bickford and Dunn, 1972), reducing that distance will have a large impact on the incident light level. Compared with scorching hot, high-intensity discharge emitters, cooler LED emitters can be brought much closer to plant tissues. LEDs, therefore, can be operated at much lower energy levels to give the same incident $P P F$ at the photosynthetic surface.

Collaboration between Purdue University and the Orbital Technologies Corporation (Madison, WI) has led to the development of a reconfigurable LED lighting array to reduce electrical input for crop lighting. Massa et al. (2005a, 2005b) described a lighting array consisting of 16 "lightsicles," each of which contains 201 -inch ${ }^{2}$ "light engines" with numerous printed-circuit LEDs. Each square light engine has columns of red and blue LEDs that are independently current-controlled to allow continuous dimming and color blending capability. The lightsicles can be arranged in a separate, vertical, intracanopy configuration whereby plants developed abnormal intumescence or edema on older leaves (Fig. 3A). This tumorlike growth did not form under higher blue light levels. 'Triton' pepper plants grown with either intracanopy or overhead $\mathrm{R}+\mathrm{B}$ LED lighting also developed severe occurrence of foliar edema. Although fruit set occurred, the extensive edema on both leaves and flower buds (Fig. 3B) strongly inhibited photosynthetic productivity (data not presented). The pepper symptoms were not mitigated by using higher percentages of blue light as occurred for cowpea. Preliminary analysis using additional ultraviolet A (365 nm) "black lights" was inconclusive, most likely as a result of the low energy flux from those lamps and unequal distances from the ultraviolet A source to the photosynthetic surfaces within a stand. 'Persimmon' tomato plants grown under the same LED lamps displayed normal growth without edema, indicating that even within solanaceous species, different susceptibilities to this physiological disorder occur. Further investigation of specific light requirements for normal growth and development of different plant species and cultivars will be required as LED lighting systems develop further.

\section{IMPORTANCE OF LEDS FOR HORTICULTURE}

Light quality plays a major role in the appearance and productivity of ornamental and food specialty crop species. Far-red light, for example, is important for stimulating flowering of long-day plants (Deitzer et al., 1979; Downs, 1956) as well as for promoting internode elongation (Morgan and Smith, 1979). Blue light is important for phototropism (Blaauw and Blaauw-Jansen, 1970), for stomatal opening (Schwartz and Zeiger, 1984), and for inhibiting seedling growth on emergence of seedlings from a growth medium (Thomas and Dickinson, 1979). The blue light photoreceptor class of cryptochromes has been found to work in conjunction with the red/FR phytochrome photoreceptor class to control factors such as circadian rhythms and de-etiolation in plants (Devlin et al., 2007). The interactions are complex and continue to be unraveled at the molecular level (Devlin et al., 2007), but much of our understanding of these responses comes from studies with narrow-waveband lighting sources, in which LEDs provide obvious advantages. Similar studies have been performed with materials that modify intercepted light quality such as colored films, mulches, or ColorNets crop netting (Polysack Plastics Industries, Israel) (Shahak et al., 2004). Thus, one potential role of LEDs in horticulture could be to enhance desired characteristics for specific crops.

In addition to changes in appearance and productivity, plant responses to narrowbandwidth light sources or to supplemental LED lighting range from decreased viral resistance in pepper to increased suppression of pathogens in tomato and cucumber to increased nitrate accumulation in spinach 



Fig. 2. Intracanopy light-emitting diode (LED) lighting (A) compared with overhead LED lighting (B) of a cowpea crop. Arrow in B shows leaf drop resulting from canopy closure and mutual shading in the overhead-lighted canopy.
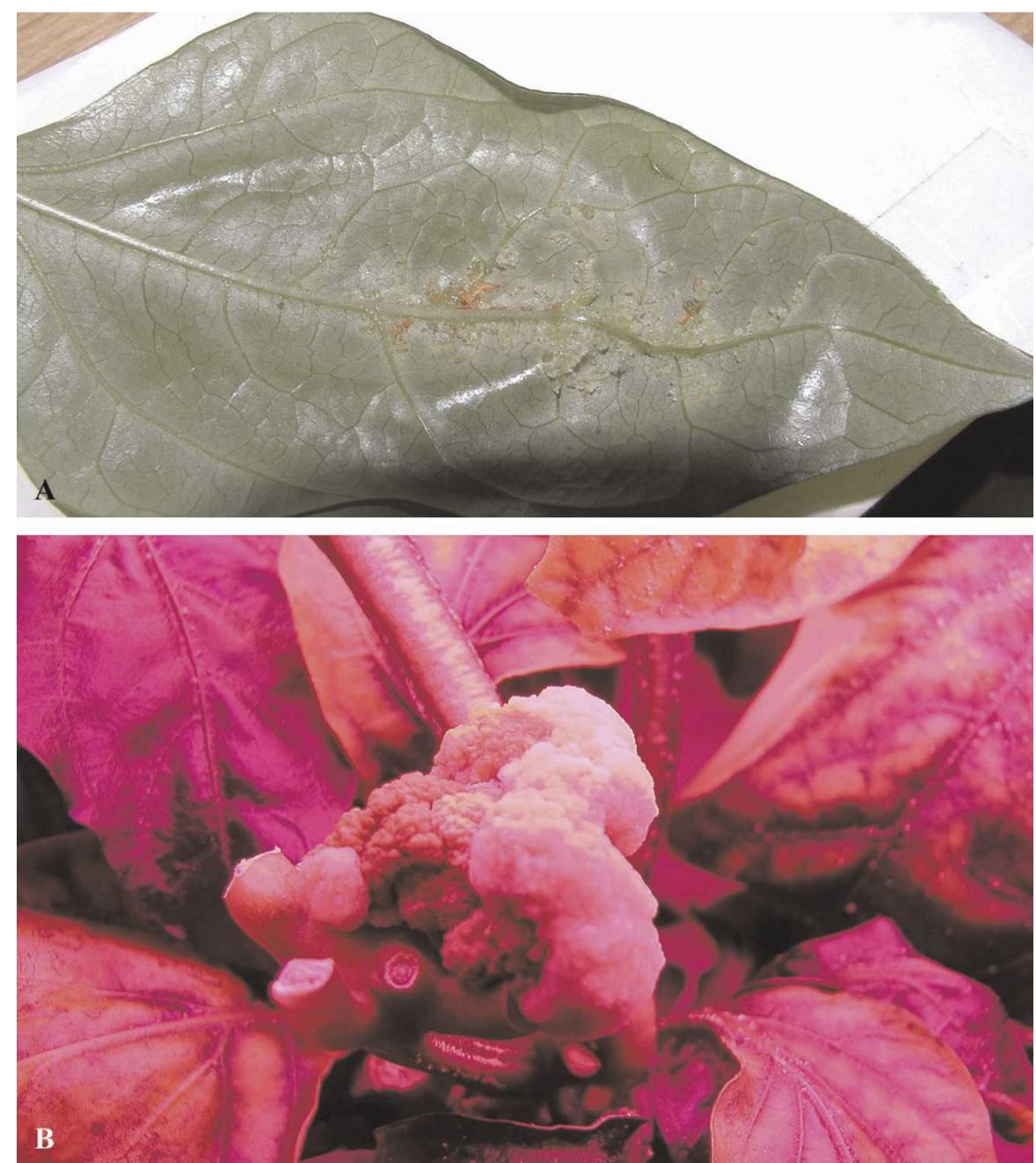

Fig. 3. Abaxial edema in a fully expanded cowpea leaf grown under less than $10 \%$ blue light-emitting diode (LED) light (A) and terminal edema in 'Triton' pepper with intumescent growths forming on the shoot apex as well as other growths occurring on flower sepals and mature and immature leaves grown at $15 \%$ blue LED light $(\mathbf{B})$.
(Kim et al., 2005 and references therein). These studies are just the tip of an as yet unmapped iceberg of crop responses to narrow-spectrum lighting. Future needs for controlled environment crop management also will involve interactions of lighting parameters with still other environmental factors. Crop breeders could, for example, select phenotypes with desirable traits expressed in response to unique lighting conditions.

New questions arise when considering LEDs for horticultural lighting in view of studies reported previously. First, what levels/proportions of red, green, and blue light will be required for particular crops? Will these optima change over the life cycle of the crop, and how should waveband ratios be modified for optimal production, whether it be yield or appearance? Data for the few species already tested already show tolerance diversity for narrow-band radiation. Better productivity generally is seen with additional wavelengths and broadening of the spectrum. This begs the question of whether we are just rediscovering the importance of white light. White LEDs do exist, but typically are blue LEDs with phosphor coatings and by their nature are less efficient than the single-wavepeak LEDs. Plant studies with these light sources remain to be performed. Perhaps LEDs used as supplements to sunlight or other types of lighting in greenhouses or growth chambers could modify crop growth or development in a desired direction without depriving crops of necessary wavelengths. The trick will be to find the right spectral and intensity combinations for each crop given that differences in light response are likely to exist even at the cultivar level.

Another issue in considering sole-source narrow-spectrum lighting with LEDs relates to visualization of plants and early detection of disease and disorder. Perhaps in species that have no absolute green light requirement, green could be used only when viewing crops for easier and clearer visualization with the human eye, and when not under observation, the energy could be redirected into other LED wavelengths.

What are some possible advantages of tailored light quality and application methods? From the data currently available, it seems likely that custom-designed lighting systems could significantly reduce insect, disease, or pathogen loads on certain crops. It is easy to imagine a lighting system enhanced or restricted in certain wavelengths that eliminates or minimizes the abilities of fungi to proliferate or insects to navigate to host species, reproduce, and so on. Although these advantages might be limited in a commercial production setting, they could be significant in growth facilities for disease-free germplasm production. Other easy-to-imagine scenarios include using select-waveband LEDs to stimulate early or uniform flowering in seasonal ornamentals or to generate specialty produce crops with enhanced levels of vitamins or minerals. Possibly treating crops with low dosages of narrow-band radiation at key points in the life cycle could initiate 
a cascade of responses in a cost-effective manner. Indeed, as LED technology continues to develop and the price of components drops, LEDs may fill many, if not all, niches of other more traditional horticultural light sources. Anticipating such eventualities now will allow horticulturists to keep pace with advances in this rapidly developing technology.

Another issue that LED technology raises for horticulture regards development of metrics for quantification of this light source. New techniques, software calibrations, and hardware must be developed to accurately quantify $P P F$ for LEDs as well as light absorbed by crops, especially for nontraditional lighting scenarios such as three-dimensional intracanopy lighting. Additional metrics of radiation capture may need to be reported to take into account parameters such as canopy volume or total energy use/cost.

An important issue for LEDs in horticulture concerns their economic viability. Like with any developing technology, as demand increases and research results accumulate, the cost of LEDs for plant growth lighting will decrease over time. For more on the economics of LEDs for plant growth, see the articles by Bourget (2008) and Morrow (2008). With advancing technology developments, LEDs are poised to become the light source with the highest electrical energy conversion ratio. Even now, LED arrays and discrete emitters with selectable, multiple colors are commercially available and are relatively inexpensive. Although many LED products do not have the capacity to produce light levels sufficient for sole-source crop lighting, a few systems do, and this number will grow. Also, less intense sources might be used in greenhouses for supplemental lighting with selected wavelengths or for night breaks in off-season production of long-day crops. Calculations need to be performed to determine breakeven points for LED cost and energy efficiency for various types of crop lighting, including sole-source lighting for CEA. With rising transportation costs and developing capabilities for local energy generation from wastes (Mitchell, 2005), LED lighting may be the key for locally produced, sustainable CEA in the future. Indeed, several "plant factories" already exist in urban areas of Japan (Cosmo Plant Co., Ltd., Fukuroi, Japan), where LEDs are used to grow lettuce for the commercial market (Ono and Watanabe, 2006). Although the breakeven point for fresh produce differs for region, population, land area, climate, transportation costs, and so on, it seems likely that LEDs will soon approach and surpass traditional crop growth lighting as an option for controlled environment production.

\section{Literature Cited}

Barta, D.J., T.W. Tibbitts, R.J. Bula, and R.C. Morrow. 1992. Evaluation of light emitting diode characteristics for space-based plant irradiation source. Adv. Space Res. 12:141149.
Bickford, E.D. and S. Dunn. 1972. Lighting for plant growth. The Kent State Univ. Press, Kent, $\mathrm{OH}$.

Blaauw, O. and G. Blaauw-Jansen. 1970. The phototropic responses of Avena coleoptiles. Acta Botan. Neer. 19:755-763.

Bourget, C.M. 2008. An introduction to lightemitting diodes. HortScience 43:1944-1946.

Brown, C.S., A.C. Schuerger, and J.C. Sager. 1995. Growth and photomorphogenesis of pepper plants grown under red light-emitting diodes supplemented with blue or far-red illumination. J. Amer. Soc. Hort. Sci. 120:808813.

Bula, R.J., R.C. Morrow, T.W. Tibbitts, D.J. Barta, R.W. Ignatius, and T.S. Martin. 1991. Lightemitting diodes as a radiation source for plants. HortScience 26:203-205.

Cosgrove, D.J. 1981. Rapid suppression of growth by blue light. Plant Physiol. 67:584-590.

Croxdale, J., M. Cook, T.W. Tibbitts, C.S. Brown, and R.M. Wheeler. 1997. Structure of potato tubers formed during spaceflight. J. Expt. Bot. 48:2037-2043.

Deitzer, G.F., R. Hayes, and M. Jabben. 1979. Kinetics and time dependence of the effect of far red light on the photoperiodic induction of flowering in Wintex barley. Plant Physiol. 64:1015-1021.

Devlin, P.F., J.M. Christie, and M.J. Terry. 2007. Many hands make light work. J. Expt. Bot. 58:3071-3077.

Downs, R.J. 1956. Photoreversibility of flower initiation. Plant Physiol. 31:279-284.

Folta, K.M. and K.S. Childers. 2008. Light as a growth regulator: Controlling plant biology with narrow-bandwidth solid-state lighting systems. HortScience 43:1957-1964.

Folta, K.M. and S.A. Maruhnich. 2007. Green light: A signal to slow down or stop. J. Expt. Bot. 58:3099-3111.

Goins, G.D., N.C. Yorio, M.M. Sanwo, and C.S. Brown. 1997. Photomorphogenesis, photosynthesis, and seed yield of wheat plants grown under red light-emitting diodes (LEDs) with and without supplemental blue lighting. J. Expt. Bot. 48:1407-1413.

Goins, G.D., N.C. Yorio, M.M. Sanwo-Lewandowski, and C.S. Brown. 1998. Life cycle experiments with Arabidopsis under red light-emitting diodes (LEDs). Life Support Biosph. Sci. 5:143149.

Hoenecke, M.E., R.J. Bula, and T.W. Tibbitts. 1992. Importance of blue photon levels for lettuce seedlings grown under red-lightemitting diodes. HortScience 27:427-430.

Johnson, C.F., C.S. Brown, R.M. Wheeler, J.C. Sager, D.K. Chapman, and G.F. Deitzer. 1996. Infrared light-emitting diode radiation causes gravitropic and morphological effects in darkgrown oat seedlings. Photochem. Photobiol. 63:238-242

Kim, H.H., G.D. Goins, R.M. Wheeler, and J.C. Sager. 2004a. A comparison of growth and photosynthetic characteristics of lettuce grown under red and blue light-emitting diodes (LEDs) with and without supplemental green LEDs. Acta Hort. 659:467-475.

Kim, H.H., G.D. Goins, R.M. Wheeler, and J.C. Sager. 2004b. Green-light supplementation for enhanced lettuce growth under red- and bluelight-emitting diodes. HortScience 39:16171622.

Kim, H.H., G.D. Goins, R.M. Wheeler, and J.C. Sager. 2004c. Stomatal conductance of lettuce grown under or exposed to different light qualities. Ann. Bot. (Lond.) 94:691-697.
Kim, H.H., R.M. Wheeler, J.C. Sager, G.D. Goins, and J.H. Norikane. 2006. Evaluation of lettuce growth using supplemental green light with red and blue light-emitting diodes in a controlled environment- $\mathrm{A}$ review of research at Kennedy Space Center. Acta Hort. 711:111119.

Kim, H.H., R.M. Wheeler, J.C. Sager, N.C. Yorio, and G.D. Goins. 2005. Light-emitting diodes as an illumination source for plants: A review of research at Kennedy Space Center. Habitation (Elmsford) 10:71-78.

Massa, G.D., J.C. Emmerich, M.E. Mick, R.J. Kennedy, R.C. Morrow, and C.A. Mitchell. 2005a. Development and testing of an efficient LED intracanopy lighting design for minimizing equivalent system mass in an advanced lifesupport system. Gravit. Space Biol. Bull. 18:87-88.

Massa, G.D., J.C. Emmerich, R.C. Morrow, and C.A. Mitchell. 2005b. Development of a reconfigurable LED plant-growth lighting system for equivalent system mass reduction in an ALS. SAE Technical Paper 2005-012955.

Massa, G.D., J.C. Emmerich, R.C. Morrow, C.M. Bourget, and C.A. Mitchell. 2006. Plantgrowth lighting for space life support: A review. Gravit. Space. Biol. 19:19-29.

Matsuda, R., K. Ohashi-Kaneko, K. Fujiwara, E. Goto, and K. Kurata. 2004. Photosynthetic characteristics of rice leaves grown under red light with or without supplemental blue light. Plant \& Cell Physiol. 45:1870-1874.

Mitchell, C. 2005. Introduction to the colloquium: Bio-derived energy sources for protected horticulture. HortScience 40:278.

Miyashita, Y., T. Kimura, Y. Kitaya, C. Kubota, and T. Kozai. 1997. Effects of red light on the growth and morphology of potato plantlets in vitro using light emitting diodes (LEDs) as a light source for micropropagation. Acta Hort. 418:169-173.

Morgan, D.C. and H. Smith. 1979. A systematic relationship between phytochrome-controlled development and species habitat, for plants grown in simulated natural irradiation. Planta 145:253-258.

Morrow, R.C. 2008. LED lighting in horticulture. HortScience 43:1947-1950.

Morrow, R.C., N.A. Duffie, T.W. Tibbitts, R.J. Bula, D.J. Barta, D.W. Ming, R.M. Wheeler, and D.M. Porterfield. 1995. Plant response in the ASTROCULTURE flight experiment unit. SAE Technical Paper 951624

Ono, E. and H. Watanabe. 2006. Plant factories blossom. Resource Mar. 2006:13-14.

Russell, J.F., G.D. Massa, and C.A. Mitchell. 2006. Water and energy transport of crops under different lighting conditions. SAE Technical Paper 2006-01-2028.

Sager, J.C. and J.C. McFarlane. 1997. Radiation, p. 1-29. In: Langhans, R.W. and T.W. Tibbitts (eds.). Plant growth chamber handbook. Iowa State Univ. Press: North Central Region Research Publication No. 340, Iowa Agriculture and Home Economics Experiment Station Special Report no. 99, Ames, IA.

Schuerger, A.C., C.S. Brown, and E.C. Stryjewski. 1997. Anatomical features of pepper plants (Capsicum annuum L.) grown under red light-emitting diodes supplemented with blue or far-red light. Ann. Bot. (Lond.) 79:273282.

Schwartz, A. and E. Zeiger. 1984. Metabolic energy for stomatal opening: Roles of photophosphorylation and oxidative phosphorylation. Planta 161:129-136. 
Shahak, Y., E.E. Gussakovsky, E. Gal, and R. Ganelevin. 2004. ColorNets: Crop protection and light-quality manipulation in one technology. Acta Hort. 659:143-151.

Stankovic, B., W. Zhou, and B.M. Link. 2002. Seed to seed growth of Arabidopsis thaliana on the International Space Station. SAE Technical Paper 2002-01-2284.

Tennessen, D.J., R.L. Singsaas, and T.D. Sharkey. 1994. Light-emitting diodes as a light source for photosynthesis research. Photosynth. Res. 39:85-92.

Thomas, B. and H.G. Dickinson. 1979. Evidence for two photoreceptors controlling growth in de-etiolated seedlings. Planta 146:545-550.
Tripathy, B.C. and C.S. Brown. 1995. Root-shoot interaction in the greening of wheat seedlings grown under red light. Plant Physiol. 107:407411.

Yanagi, T., K. Okamoto, and S. Takita. 1996a. Effect of blue and red light intensity on photosynthetic rate of strawberry leaves. Acta Hort. 440:371-376.

Yanagi, T., K. Okamoto, and S. Takita. 1996b. Effect of blue, red, and blue/red lights of two different PPF levels on growth and morphogenesis of lettuce plants. Acta Hort. 440:117-122.

Yorio, N.C., G.D. Goins, H.R. Kagie, R.M. Wheeler, and J.C. Sager. 2001. Improving spinach, radish, and lettuce growth under red light-emitting diodes (LEDs) with blue light supplementation. HortScience 36:380-383.

Yorio, N.C., R.M. Wheeler, G.D. Goins, M.M. Sanwo-Lewandowski, C.L. Mackowiak, C.S. Brown, J.C. Sager, and G.W. Stutte. 1998. Blue light requirements for crop plants used in bioregenerative life support systems. Life Support Biosph. Sci. 5:119128.

Zhou, W. 2005. Advanced Astroculture ${ }^{\mathrm{TM}}$ plant growth unit: Capabilities and performances. SAE Technical Paper 2005-012840. 